\title{
Targeted Violence: A Review of the Literature on Radicalization and Mobilization
} Megan K McBride, $\mathrm{PhD}^{1}$; Marley Carroll; Jessa L Mellea; and Elena Savoia, MD, MPH

This project is sponsored by the U.S. Department of Homeland Security (DHS), Science \& Technology Directorate award \#21STFRG00012-01-00 Blue Campaign Program Evaluation, TTA\#2 Scientific Advisement. The content of this presentation is solely those of the author and does not necessarily represent the views of any partner organizations or the DHS.

October 7, 2021

\begin{abstract}
$\underline{\text { Abstract }}$
This literature review contributes to the work of understanding the differences between targeted violence and domestic terrorism by exploring research on radicalization and mobilization processes within the literature on targeted violence. This review relied on DHS's 2019 language regarding the definition of targeted violence, and consequently focused on incidents that lacked an ideological motivation and occurred in "communities, schools, places of worship, and other public gatherings." Though our data collection returned 169 distinct articles seemingly on the radicalization or mobilization of those involved in terrorism and targeted violence, we did not find a robust discussion of processes of radicalization or mobilization of those who commit acts of targeted violence. We did, however, identify five "theories of radicalization" in the targeted violence literature which we review in the article. We then articulate recommendations for research that would improve understanding of how domestic terrorism and targeted violence are related. This work is especially critical because the literatures on these topics are not, at present, in conversation with one another, and bringing them together has the potential to meaningfully advance the understanding of both phenomena.
\end{abstract}

\section{Introduction}

The phrase "targeted violence" is over 25 years old (it was first used in a 1995 paper titled "Threat Assessment: An Approach to Prevent Targeted Violence"). ${ }^{2}$ Recently, though, the language has transitioned from a term of art to a descriptor just as likely to appear in a newspaper article or an academic journal. In fact, over half of the Google Scholar results for a query of "targeted violence" are for articles written in the past five years. Yet despite this increased use, the phrase is at best vaguely defined. According to the Department of Homeland Security's (DHS) 2019 Strategic Framework, targeted violence includes:

Any incident of violence that implicates homeland security and/or U.S. Department of Homeland Security activities, and in which a known or knowable attacker selects a

\footnotetext{
${ }^{1}$ Harvard School of Public Health, corresponding author, mmcbride@hsph.harvard.edu.

${ }^{2}$ Fein, Robert A., Bryan Vossekuil, and Gwen A. Holden. Threat assessment: An approach to prevent targeted violence. Vol. 2. US Department of Justice, Office of Justice Programs, National Institute of Justice, 1995.
} 
particular target prior to the violent attack. Unlike terrorism, targeted violence includes attacks otherwise lacking a clearly discernible political, ideological, or religious motivation, but that are of such severity and magnitude as to suggest an intent to inflict a degree of mass injury, destruction, or death commensurate with known terrorist tactics. In the Homeland, targeted violence has a significant impact on the safety and security of our communities, schools, places of worship, and other public gatherings. ${ }^{3}$

The strategic framework acknowledges that the line between terrorism and targeted violence can be difficult to discern, and raises the possibility that there may be "some alignment in the tools that can be used to counter them."

This literature review contributes to the work of understanding the differences between targeted violence and domestic terrorism by exploring research on radicalization and mobilization processes within the literature on targeted violence. The ultimate goal of this work is to inform policy, practice and future research by establishing whether or not the hypothesized processes of radicalization being used to describe those who engage in acts of targeted violence are similar to, or different from, the hypothesized processes of radicalization being used to describe those who commit acts of domestic terrorism. Determining whether or not these processes are similar or different is critical to policymakers and government officials and practitioners working to create the institutions and programs necessary to prevent both types of violence. If perpetrators of both domestic terrorism and targeted violence radicalize via similar processes, then it may be possible to leverage the resources dedicated to preventing domestic terrorism to address both challenges. By contrast, if the perpetrators radicalize via different processes, then more significant adjustments might be necessary in order to align existing domestic terrorism resources to address targeted violence.

The search and synthesis strategy we adopted included: querying for articles that propose theories of radicalization, examining case studies to determine which theories of radicalization are being used, expanding search terms to include distinct phrases that might return more results, and analyzing comparative literature (i.e., literature explicitly looking at the similarities and differences between terrorism and targeted violence). We then consulted with experts in the field (i.e., scholars who write on acts that fit the definition of targeted violence) to validate our findings. Despite the lack of literature on this topic, this review was ultimately able to identify a number of theories of radicalization that have been proposed by those working in this space.

\section{Background}

\footnotetext{
${ }^{3}$ U.S. Department of Homeland Security, Strategic Framework for Countering Terrorism and Targeted Violence (2019), 4, https://www.dhs.gov/sites/default/files/publications/19_0920_plcy_strategic-framework-countering-terrorism-targete d-violence.pdf. Violence, 4.

${ }^{4}$ U.S. Department of Homeland Security, Strategic Framework for Countering Terrorism and Targeted
} 
Our approach to the definition of radicalization and mobilization, in the context of this paper, was influenced by recent work in terrorism studies on the importance of differentiating between beliefs and actions. Efforts to separate the two concepts stemmed from dissatisfaction with a composite model that did not explain why many individuals radicalize without engaging in terrorist violence. Though we adopt Stern's language of radicalization and mobilization, it is consistent with McCauley and Moskalenko's distinction between the "opinion pyramid" and the "action pyramid" and Horgan's distinction between radicalization and violent radicalization. ${ }^{5}$ We thus define radicalization as the social and psychological process through which an individual or group adopts extreme beliefs, ideas, or opinions. ${ }^{6}$

Since mobilization is infrequently discussed in isolation in terrorism literature, we have derived our definition of the term from Horgan's definitions of both disengagement and violent radicalization. Horgan defines disengagement as "the process whereby an individual experiences a change in role or function that is usually associated with a reduction of violent participation."7 By contrast, he defines "violent radicalisation" as "the social and psychological process of increased and focused radicalisation through involvement with a violent non-state movement," including within that both initial and continuing involvement with a violent extremist group. ${ }^{8}$ Both definitions focus on change in an individual's behaviors, though the latter frames these behavioral changes as a mechanism for radicalization. Further, both definitions present these processes as occurring within a group setting. We follow this scholarship, though we broaden it to include lone actors, and define the term mobilization as the behavioral process of planning and preparing to commit an act of terrorism or targeted violence, often culminating in the perpetration of such acts. Importantly, our definition of mobilization does not presuppose a motivating political cause or ideology, and focuses on the process leading to a single attack rather than an individual's lifetime involvement and behaviors. As such, it is especially well-suited to discussions of targeted violence which are characterized — at least in part — by the absence of a motivating political, religious, or ideological agenda.

Because this distinction is not universal within the literature that we were searching, we included the language necessary to capture both radicalization and mobilization in our boolean strings. Our intention was to differentiate between the two in our analysis, essentially comparing both theories of radicalization and mobilization for both domestic terrorism and targeted violence. There was, however, very little literature specifically addressing the processes of

\footnotetext{
5 Jessica Stern, "Radicalization to Extremism and Mobilization to Violence," The ANNALs of the American Academy of Political and Social Science 668, no. 1 (2016); John Horgan, Walking Away from Terrorism: Accounts of Disengagement from Radical and Extremist Movements (New York: Routledge, 2009); Clark McCauley and Sophia Moskalenko, "Understanding Political Radicalization: The Two-Pyramids Model," American Psychologist 72 (April 2017): 205-216.

${ }^{6}$ John Horgan, Walking Away from Terrorism: Accounts of Disengagement from Radical and Extremist Movements (New York: Routledge, 2009), 152.

${ }^{7}$ Horgan, Walking Away from Terrorism, 152.

${ }^{8}$ Horgan, Walking Away from Terrorism, 152.
} 
radicalization or mobilization for those who engage in targeted violence. Thus, though the distinction was not as relevant as we expected, we do maintain it in our analysis.

\section{Methodology}

Unfortunately, for a number of reasons, the phrase "targeted violence" does not function as an especially strong search term in the academic literature. To begin, the term is relatively new, meaning that many incidents that might be described as targeted violence occurred before the phrase was in widespread use. The 2017 Las Vegas shooting, for example, happened two years before the 2019 DHS Strategic Framework was written; and the Columbine school shooting happened just four years after the term was coined (and well before it had become more mainstream). Additionally problematic is that the lines separating acts of targeted violence from acts of domestic terrorism are at best blurry. As a result, these incidents can be difficult to classify for a variety of reasons including, but not limited to: if law enforcement officials do not find a political/ideological/religious motivation (e.g., Las Vegas); if the perpetrator's ideology appears to be thin or inconsistent (e.g., Omar Mateen); or if scholars are uncertain that a political/ideological motivation is cohesive (e.g., violent incels). This uncertainty and ambiguity is then reflected in the literature. As one example, articles on Anders Breivik describe him as a "far-right terrorist," "lone wolf terrorist," and "mass shooter." Scholars from different disciplines and backgrounds are consequently applying the terms unevenly and inconsistently, complicating the process of finding the relevant articles. Moreover, there are no strong proxy terms that can stand in for targeted violence. Following the lead of DHS, this literature review focused on violence targeting "communities, schools, places of worship, and other public gatherings." A query focusing on locations, though, can easily return results that are commonly classified as domestic terrorism (e.g., Wade Michael Page's attack on a Sikh temple or Dylann Roof's attack at a Christian church). In short, even the relatively straightforward task of identifying the articles upon which to base this literature review was unexpectedly complicated. To address this challenge we developed the methodology outlined below, which consists of an iterative process distinguished in two phases - informed and shaped by what we learned along the way - that resulted in our final dataset.

\section{Search Strategy - Phase 1}

As mentioned above, this literature review used DHS's 2019 language regarding the definition of targeted violence to inform its data collection. This language explicitly mentions four broad types of violence based on the location of the incident: that which occurs in

\footnotetext{
${ }^{9}$ Anne Maria Möller-Leimkühler, "Why is terrorism a man’s business?,” CNS Spectrums 23 (2018): 119; Lars Erik Berntzen and Sveinung Sandberg, "The Collective Nature of Lone Wolf Terrorism: Anders Behring Breivik and the Anti-Islamic Social Movement," Terrorism and Political Violence 26, no. 5 (2014): 759; L. Faccini and C.S. Allely, "Mass violence in individuals with Autism Spectrum Disorder and Narcissistic Personality Disorder: A case analysis of Anders Breivik using the 'Path to Intended and Terroristic Violence' Model," Aggression and Violent Behavior 31 (November-December 2016): 231.
} 
"communities, schools, places of worship, and other public gatherings." We added to this list violence that occurs in workplaces, as well as a number of phrases and terms (e.g., "mass shooting" and "lone wolf") that we thought might capture the types of attacks we were interested in. We conducted searches using the databases Web of Science, Social Science Premium, Policy File, PsycINFO, International Bibliography of the Social Science, and Criminal Justice Abstracts with Full Text using the following four boolean strings:

1. su((“targeted violence") AND (radicali* OR mobili* OR engage* OR path* OR process*)) OR ti((“'targeted violence”) AND (radicali* OR mobili* OR engage* OR path* OR process*))

2. $\operatorname{su}($ ("school shoot*" OR "workplace shoot*" OR "mass shoot*" OR "mass kill*" OR rampage* OR massacre* OR “mass violence”) AND (radicali* OR mobili* OR engage* OR path* OR process*)) OR ti((“school shoot*" OR "workplace shoot*” OR "mass shoot*” OR "mass kill*” OR rampage* OR massacre* OR "mass violence") AND (radicali* OR mobili* OR engage* OR path* OR process*))

3. $\operatorname{su}($ ("church shoot*" OR "synagogue shoot*" OR "mosque shoot*" OR "temple shoot*”) AND (radicali* OR mobili* OR engage* OR path* OR process*)) OR ti((“church shoot*" OR "synagogue shoot*" OR "mosque shoot*" OR "temple shoot*”) AND (radicali* OR mobili* OR engage* OR path* OR process*))

4. (su((extremis* OR terroris*) AND (radicali* OR mobili* OR engage* OR path* OR process*)) OR ti((extremis* OR terroris*) AND (radicali* OR mobili* OR engage* OR path* OR process*))) AND ti(review)

For the first three boolean strings, we stipulated that the article had to (i) have been published after January 1, 2000, (ii) be published in a peer-reviewed journal, and (iii) be written in English. Because our search was completed in August 2021, this strategy returned approximately 21 years of peer-reviewed, English-language articles on the radicalization or mobilization of perpetrators of targeted violence. For the last boolean string, we narrowed the scope so as to include only articles published after January 1, 2010, thus returning approximately 11 years of peer-reviewed, English-language review articles on the radicalization of terrorists and extremists.

Finally, after noticing that the targeted violence literature often referenced attacks using the terms "lone wolf," "lone actor," and "active shooter," we expanded our query (search term for query \#5 reported below) to include these terms. 
5. su((“lone wolf” OR "lone-wolf” OR "lone actor" OR "lone-actor" OR "active shooter") AND (radicali* OR mobili* OR engage* OR path* OR process*)) OR ti((“lone wolf” OR “lone-wolf” OR "lone actor" OR “lone-actor" OR “active shooter”) AND (radicali* OR mobili* OR engage* OR path* OR process*))

The first data collection phase of this project yielded a total of 1,353 original articles. The electronic results of these queries were exported in RIS files from these databases and were added to Covidence, which the research team used to conduct a title and abstract screening. The articles that had no direct relevance to radicalization, mobilization, or engagement processes for terrorists, extremists, or perpetrators of targeted violence were removed from the dataset and marked as irrelevant. Two reviewers screened each article and if they could not agree on its classification, a third reviewer was consulted. After the title and abstract screening, the remaining articles were exported to a single shared Google Sheet and full-text versions of the articles were downloaded.

\section{Search Strategy - Phase 2}

Once we started the full-text screening of articles, we ran additional searches based on our findings. Our initial review of the articles, for example, allowed us to identify two models resembling radicalization or mobilization theories: the Path to Intended Violence model and the Sequential Model. For the Path to Intended Violence model, we first located the source of the model, and then screened articles that cited the work from which the model originated. By doing so, we found four additional articles relevant to our review, as well as two that had already appeared in previous queries. For the Sequential Model, we conducted a similar review but did not find any additional articles relevant to this review. Instead, we found articles that focused on issues other than radicalization, such as risk factors, mental health issues, and attack patterns. We also ran additional queries tracking down ideas prompted by our initial research. We then conducted searches using the following potential keywords and themes in an effort to determine whether they might lead to additional research relevant to our literature review: "ideological shooter," "nonideological shooter," and "grievance fueled violence." Each query yielded additional articles that we added to our dataset.

Finally, because the data we had returned was overwhelmingly focused on school shootings and youth violence, we ran a series of queries to determine whether additional literature on other forms of targeted violence existed but was not being identified by our boolean strings. As one example, we ran a number of queries on the 2017 Las Vegas shooting to see how it had been described and to determine if there was other language we should be using. These queries provided no additional sets of literature for us to examine, thus substantiating that our boolean strings and follow-up queries had captured the desired targeted violence literature.

\section{Coding}


Once the data collection phase was complete, our dataset consisted of 169 articles related to the radicalization, mobilization, or engagement processes or pathways of terrorists, extremists, or perpetrators of targeted violence. We then reviewed each of the articles in the dataset and used the titles and abstracts to mark them as relating to either terrorism, targeted violence, or both.

We classified articles as relating to terrorism according to the Global Terrorism Database's definition of terrorism as "the threatened or actual use of illegal force and violence by a non-state actor to attain a political, economic, religious, or social goal through fear, coercion, or intimidation." ${ }^{10}$ Within that, we distinguish between domestic and international terrorism using the Federal Bureau of Investigation's definitions. The Bureau defines international terrorism as being "committed by individuals and/or groups who are inspired by, or associated with, designated foreign terrorist organizations or nations (state-sponsored)" and domestic terrorism as "committed by individuals and/or groups to further ideological goals stemming from domestic influences, such as those of a political, religious, social, racial, or environmental nature." "We categorized articles as "non-U.S. domestic terrorism" when they met the FBI definition of domestic terrorism but occurred in a different country. Finally, articles were categorized as "general terrorism" if they did not have a particular regional, ideological, or group focus and/or were theoretical in nature.

For targeted violence, we used the DHS description of targeted violence as violent incidents in which the perpetrator selects the attack target prior to the incident, focusing on "attacks otherwise lacking a clearly discernible political, ideological, or religious motivation." 12 In cases where an article's focus was unclear, we read the full article before classifying it. The process of coding the articles was complicated by the fact that in some cases the authors would use language suggesting inclusion in both categories. One article, exploring in part how to classify these types of attacks, described a particular event in Sweden as: a "school shooting" (in the keywords), a "school attack," a "targeted attack," "targeted violence," "terrorism," "individual terrorism," and "lone actor terrorism". ${ }^{13}$ Other articles complicated this process by intentionally addressing both types of violence in an effort to explore similarities and differences between them.

Importantly, our coding approach — designed to mitigate the problem of inconsistency in the use of the language - meant that our research team classified the articles without regard to how the original scholars had described their own work. In other words, our team assessed how

\footnotetext{
${ }^{10}$ National Consortium for the Study of Terrorism and Responses to Terrorism (START), University of Maryland. (2019). The Global Terrorism Database (GTD) Codebook, https://www.start.umd.edu/gtd/.

11 “Terrorism," Federal Bureau of Investigation, accessed September 27, 2021, https://www.fbi.gov/investigate/terrorism.

${ }^{12}$ U.S. Department of Homeland Security, Strategic Framework for Countering Terrorism and Targeted Violence (2019), 4, https://www.dhs.gov/sites/default/files/publications/19_0920_plcy_strategic-framework-countering-terrorism-targete d-violence.pdf.

${ }^{13}$ Åsa Erlandsson and J. Reid Meloy. "The Swedish school attack in Trollhättan." Journal of forensic sciences 63, no. 6 (2018): 1917-1927.
} 
to classify an article based solely on the data in the article and the definitions cited above. The graphic below captures our assessment of the full dataset. ${ }^{14}$

\section{FOCAL CATEGORIES OF VIOLENCE IN ARTICLES}

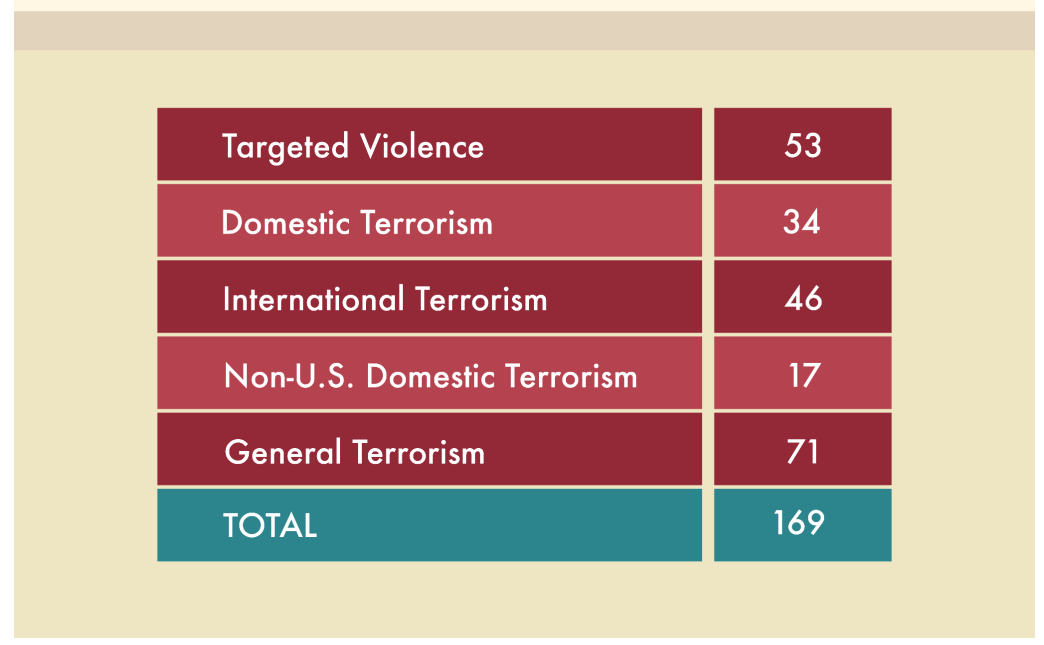

As a final note, our decision to independently classify the articles raised the obvious question of how frequently we were in agreement with the authors, so we also assessed how the authors had classified their own articles. We did so by looking in the text for the terms "terrorism" and "targeted violence," as well as very closely related terms (e.g., "targeted attack" but not "mass shooting"). We found that our classification matched that of the authors $71 \%$ of the time. Most of the discrepancies, $21 \%$ of the articles, were a result of the authors failing to use either of the primary categories we were analyzing (i.e., targeted violence or terrorism). We classified nearly all of these cases (32 of 35 articles) as targeted violence, which was unsurprising given that it is both a newer and less clearly defined category

${ }^{14}$ When an article fell into multiple categories, we included it in multiple categories, which is why the sum of the articles in the table (221) exceeds our total number of articles (169). 


\section{CATEGORIZATION AGREEMENT BETWEEN ARTICLE AUTHORS AND RESEARCH TEAM}

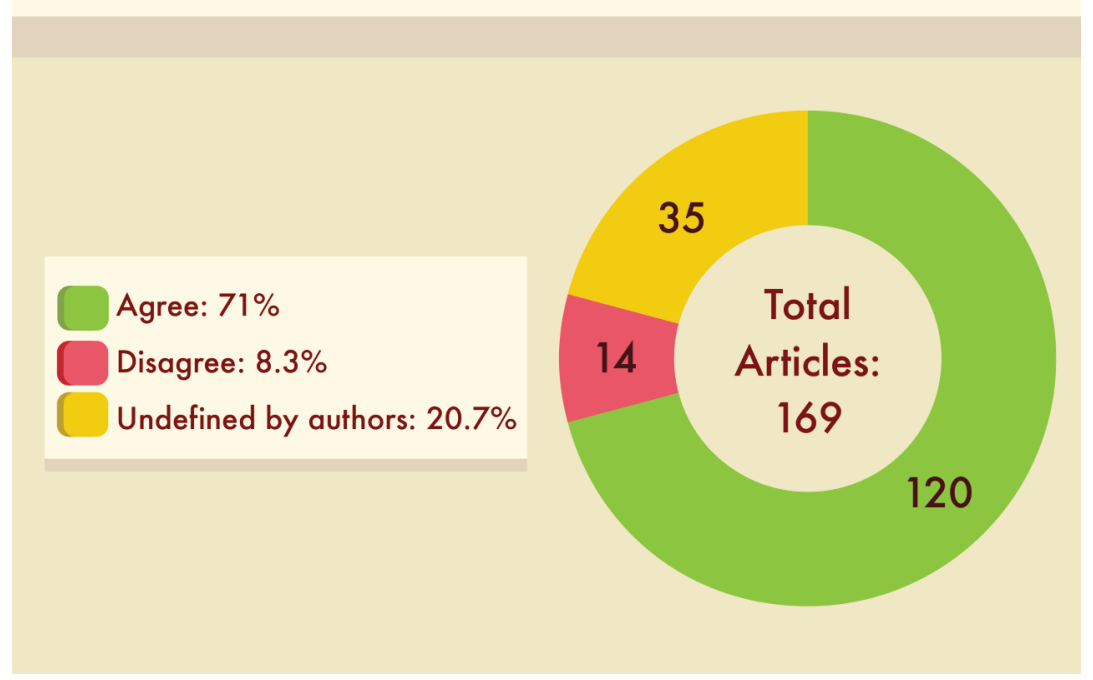

\section{Literature Synthesis}

\section{Theories of radicalization and mobilization}

Though our data collection returned 169 distinct articles seemingly on the radicalization or mobilization of those involved in terrorism and targeted violence, a closer examination revealed that there were actually very few articles in the latter category. In other words, we did not find a robust discussion of processes of radicalization or mobilization in the targeted violence literature. Yet we found five "theories of radicalization" in the literature we reviewed: 1) Sequential Model, 2) Unnamed Shame and Developmental Trajectories Model, 3) Path to Violence, 4) Developmental Pathways to Demonstrative Target Attacks, and 5) Intimate Massacre Model. A summary of each model is provided below.

\section{Theory 1: Sequential Model}

One article, "Mass Murder at School and Cumulative Strain: A Sequential Model," outlined and applied a five-stage sequence that elaborates on distinct strains (defined here as "difficulties that lead to anger, frustration, disappointment, depression, fear, and ultimately, crime" in an individual's life). ${ }^{15}$ This sequential model combines three criminological theories established to explain crime more broadly - general strain theory, social control theory, and routine-activities theory-and applies them to explain how psychosocial factors compound to impel an individual to commit mass murder. The model begins with chronic strain, defined as the presence of persistent life difficulties over a long period of time.${ }^{16}$ Chronic strain alone is relatively common; therefore, it must be accompanied by uncontrolled strain, the second stage of the model. Uncontrolled

\footnotetext{
15 Jack Levin and Eric Madfis, "Mass Murder at School and Cumulative Strain: A Sequential Model," American Behavioral Scientist 52, no. 9 (May 2009): 1230.

${ }^{16}$ Levin and Madfis, "Mass Murder at School and Cumulative Strain,” 1230.
} 
strain refers to the breakdown or absence of prosocial support systems as a result of social isolation. ${ }^{17}$ The third stage consists of an acute strain, "some loss perceived to be catastrophic in the mind of the killer, which serves as a catalyst or precipitant" for the fourth and fifth stages, the planning and commencement of the massacre, respectively. ${ }^{18}$ The latter two stages describe mobilization more than radicalization; however, the authors do describe the planning stage as the time during which "a mass killing is fantasized about as a masculine solution to regain lost feelings of control" in addition to the explicit preparatory actions. ${ }^{19}$ Despite being the most complete radicalization theory that we found in the targeted violence literature, this sequential model only appeared in our queries in the article in which it was theorized. A follow-on query revealed that the article was well cited (with over 250 citations listed in Google Scholar), but analysis of these articles revealed virtually no case studies applying the model to individual offenders. Instead, this literature was largely focused on: risk factors and correlates of mass violence; training on, and prevention of, school shootings; leakage and behavior antecedent to attacks; and the impact of attacks on students, teachers, and society.

\section{Theory 2: Unnamed Shame and Developmental Trajectories Model}

The second article articulating a radicalization theory, "The Role of Shame in Developmental Trajectories Towards Severe Targeted School Violence: An In-Depth Multiple Case Study," examined how shame may intervene in developmental trajectories to push individuals toward school-based targeted violence. Examining 19 cases of school-based targeted violence, the study identifies three psychological turning points preceding acts of violence: two shame crises and a triggering event. The first shame crisis occurs as a result of the revelation of an individual's weakness to others, while the second stems from the individual's failed attempts at managing the shame brought on by the first crisis. ${ }^{20}$ However, the authors identify two distinct ways in which perpetrators attempt to manage their shame - internalization, or social withdrawal, and externalization, or aggressive behavior - that shape the rest of their radicalization process. ${ }^{21}$ Following the second shame crisis, individuals begin to plan a violent attack; however, this planning process differs for type 1 (internalizing) versus type 2 (externalizing) individuals. Whereas type 1 perpetrators need to transform their self-image from weak to powerful in order to build the requisite aggression and hostility needed to decide to commit an attack,

\footnotetext{
${ }^{17}$ Levin and Madfis, "Mass Murder at School and Cumulative Strain," 1233.

${ }^{18}$ Levin and Madfis, "Mass Murder at School and Cumulative Strain," 1235.

${ }^{19}$ Levin and Madfis, "Mass Murder at School and Cumulative Strain," 1227.

${ }^{20}$ Friederike Sommer, Vincenz Leuschner, Nora Fiedler, Eric Madfis, and Herbert Scheithauer, "The role of shame in developmental trajectories towards severe targeted school violence: An in-depth multiple case study," Aggression and Violent Behavior 51 (2020): 4.

${ }^{21}$ Sommer, et al., "The role of shame in developmental trajectories towards severe targeted school violence," 6 .
} 
type 2 perpetrators already see themselves as powerful and aggressive, and thus go through a shorter planning phase focused more on outward identification with violence. ${ }^{22}$ Following the triggering event, both types enter a short preparation phase, then commit the offense itself. ${ }^{23}$ Like the sequential model, the latter two steps align more closely with mobilization than radicalization. Also noteworthy is that the Developmental Pathways to Demonstrative Targeted Attacks model (Theory 4, below) adds to this discussion by outlining how each perpetrator type's respective developmental trajectory impacts thinking with regard to announcement of intentions to attack (leakage) and target selection during the attack itself. While the theory is based on case studies of 19 incidents of school-based targeted violence, no case studies walk through the shame-focused developmental model from start to finish and this theory does not appear in any other articles that came up in our queries. Moreover, a follow-on query revealed that this research has been cited just twice (both times in articles written by some of the same authors who developed the theory). In each case, however, the citation was used in the context of work on prevention programming. ${ }^{24}$

\section{Theory 3: Path to Violence (family of theories)}

The third theory, the Path to Intended Violence, originally arose in the field of threat assessment as a means to evaluate assassins acting individually and targeting high profile individuals. In the model, articulated by Calhoun and Weston in 2003, the perpetrator moves "from feeling a grievance to developing the idea that only violence can resolve their injury, to researching and planning the attack, to making preparations according to the dictates of the plan...to breaching the target's security...to attack." ${ }^{25}$ This theory was later adapted in a 2005 master's thesis by Olson, who used it to explain the radicalization of extremist groups. ${ }^{26}$ This adaptation, called the Path to Terrorist Violence (PTTV), includes similar but slightly modified stages (e.g., the model's first stage of feeling a grievance, includes not only personal grievances but also political ones). In the targeted violence literature, this theory was found in the work of Allely and Faccini who adapted violence," 7.

${ }^{22}$ Sommer, et al., "The role of shame in developmental trajectories towards severe targeted school

${ }^{23}$ Sommer, et al., "The role of shame in developmental trajectories towards severe targeted school violence," 8 .

${ }^{24}$ Nora Fiedler, Friederike Sommer, Vincenz Leuschner, Nadine Ahlig, Kristin Göbel, and Herbert Scheithauer, "Teacher and peer responses to warning behavior in 11 school shooting cases in Germany," Frontiers in Psychology 11 (2020); Nora Fiedler, Vincenz Leuschner, Friederike Sommer, Dewey Cornell, and Herbert Scheithauer, "Assessing Implementation Fidelity of a School-Based Crisis Prevention Program with an Ex-Post-Facto Design: The NETWASS FOI Assessment System," International Journal of Developmental Science 14, no. 1-2 (2020): 27-40.

${ }^{25}$ Frederick S. Calhoun and Stephen W. Weston, "Perspectives on Threat Management," Journal of Threat Assessment and Management 2 (2015): 3-4, 259.

${ }^{26}$ D. Olson, "The Path to Terrorist Violence: A Threat Assessment Model for Radical Groups at Risk of Escalation to Acts of Terrorism," (2005). 
the theory (calling it the Path to Intended and Terroristic Violence model) to explain examples of both terrorism and targeted violence in a series of articles. Importantly, these articles (one of which focused on targeted violence perpetrator Adam Lanza; three of which focused on terrorists Elliot Rodger, Anders Breivik, and Dylann Roof; one of which focused on Anders Breivik, Dean Allen Mellberg, and Adam Lanza; and one of which focused on 75 individuals in the Mother Jones mass shooting database) focus exclusively on the association between Autism Spectrum Disorder (ASD) and acts of violence. ${ }^{27}$ Broadly, they posit that a relationship between the Path to Intended Violence (sometimes the Path to Intended and Terroristic Violence) and ASD (sometimes in combination with comorbid diagnoses of a Personality Disorder) might explain the violent behavior of this small subset of perpetrators. All of the articles that included the model also analyzed risk factors that may contribute to this violence.

\section{Theory 4: Developmental Pathways to Demonstrative Targeted Attacks}

The fourth theory, outlined in "Same but Different? Developmental Pathways to Demonstrative Targeted Attacks - Qualitative Case Analyses of Adolescent and Young Adult Perpetrators of Targeted School Attacks and Jihadi Terrorist Attacks in Germany," sought to explain the pathways to violence for perpetrators of both targeted violence and terrorism. ${ }^{28}$ This model was based on a sample of 35 cases of targeted school violence perpetrators and 21 cases of terrorists, all of whom committed an attack in Germany between 1999 and 2013. The two sets of perpetrators follow nearly the same developmental pathway, with only slight differences. The model begins with the individual's mental dispositions, as well as mental disorders, that frame how they process reality and the world. Next, grievances arise, on a continuum from personal to political.

${ }^{27}$ Lino Faccini, "The application of the models of autism, psychopathology and deficient Eriksonian development and the path of intended violence to understand the Newtown shooting," Archives of Forensic Psychology 1.3 (2016): 1-13; C.S. Allely and L. Faccini, "Path to intended violence, a model to understand mass violence in the case of Elliot Rodger," Aggression and Violent Behavior 37 (2017); C.S. Allely and L. Faccini, "Mass violence in individuals with Autism Spectrum Disorder and Narcissistic Personality Disorder: A case analysis of Anders Breivik using the 'Path to Intended and Terroristic Violence' model" Aggression and Violent Behavior 31 (2016); C.S. Allely and L. Faccini, "Clinical profile, risk, and critical factors and the application of the "path toward intended violence" model in the case of mass shooter Dylann Roof," Deviant Behavior 40 (2019): 6; C. S. Allely and L. Faccini, "A Conceptual Analysis of Individuals with an Autism Spectrum Disorder engaging in Mass Violence," Journal of Forensic and Crime Studies 1.1 (2017): 1-5; C.S. Allely, P. Wilson, H. Minnis, L. Thompson, E. Yaksic,and C. Gillberg, "Violence is Rare in Autism: When It Does Occur, Is It Sometimes Extreme?," Journal of Psychology 151 (2017): 1. Notably, neither Faccini's 2016 article on Lanza nor Allely and Faccini's 2017 article on Brevik/Mellberg/Lanza are part of our dataset. Both were identified via follow-on research which also yielded an additional article on Dean Allen Mellberg that we were unable to access or review: Lino Faccini and Clare S. Allely, "Mass Violence in an Individual with an Autism Spectrum Disorder: A Case Analysis of Dean Allen Mellberg using the 'Path to Intended Violence' Model," International Journal of Psychology Research 11.1 (2016).

${ }^{28}$ Nils Böckler, Vincenz Leuschner, Viktoria Roth, Andreas Zick, and Herbert Scheithauer, "Same but Different? Developmental Pathways to Demonstrative Targeted Attacks — Qualitative Case Analyses of Adolescent and Young Adult Perpetrators of Targeted School Attacks and Jihadi Terrorist Attacks in Germany," International Journal of Developmental Science 12 (2018): 13. 
In the study's sample of school attackers and terrorist attackers, school attackers clustered towards the personal end of the continuum and terrorist attackers were closer to the political end. From there, the perpetrators began to identify with previous attackers and "ideological [or] cultural scripts" of violence. This model combines radicalization and mobilization into one process, with radicalization (for terrorist attackers) beginning at this stage in the model. After the step of identification, perpetrators move into the redefinition of self, wherein their increasing identification with a violence-justifying worldview transforms their perception of themselves from that of a nobody or a failure to that of someone who is significant and worthy of recognition. This stage is followed by clandestine planning of the attack, either alone or in small groups, and often with ritualized elements. Trigger events, which can vary, then push the perpetrator to an act of violence. Another article, "Blurred Boundaries of Lone-Actor Targeted Violence: Similarities in the Genesis and Performance of Terrorist Attacks and School Shootings," written by the same authors, also used this model. ${ }^{29}$

\section{Theory 5: Intimate Massacres Model}

The fifth model is somewhat unique in that it does not offer a clear radicalization process, but instead suggests multiple explanations for radicalization without explicitly ordering them. The article, "A Theory of Intimate Massacres: Steps Toward a Causal Explanation," identifies three factors as potentially explaining why individuals commit "intimate massacres": seeking a point of no return, negating others' personification of them, and bringing order to emotional chaos. ${ }^{30}$ The article frames intimate massacres as "'intimate' because the site targeted has biographical meaning to the attacker, as terrorist attacks do not, 'massacre' because, unlike revenge attacks, there is an indiscriminate targeting of victims." ${ }^{31}$ According to the article, these attacks are a perpetrator's way of transforming their identity "by negating their past in an ineradicable way," which is seen as a means of destroying "the person others have assumed one to be" without destroying one's conception of oneself. ${ }^{32}$ This model posits that perpetrators' failed attempts to fit in solidifies their "public identity as awkward, impenetrable, loner, strange, or mentally ill," which in turn reinforces their socialization difficulties. ${ }^{33}$ These repeated failed attempts represent a form of internal chaos; by committing an intimate massacre, "the assailant is attempting to... crystallize chaos in a representation of order." ${ }^{34}$ That is, the perpetrator

\footnotetext{
${ }^{29}$ Nils Böckler, Vincenz Leuschner, Viktoria Roth, Andreas Zick, and Herbert Scheithauer, "Blurred Boundaries of Lone-Actor Targeted Violence: Similarities in the Genesis and Performance of Terrorist Attacks and School Shootings," Violence and Gender 5, no. 2 (2018): 7-80.

${ }^{30}$ Jack Katz, "A theory of intimate massacres: Steps toward a causal explanation," Theoretical Criminology 20, no. 3 (2016): 277.

${ }^{31} \mathrm{Katz}$ " "A theory of intimate massacres," 278.

${ }^{32} \mathrm{Katz}$, "A theory of intimate massacres," 284.

${ }^{33} \mathrm{Katz}$, "A theory of intimate massacres," 291.

${ }^{34} \mathrm{Katz}$, “A theory of intimate massacres," 289.
} 
seeks to impose a sense of temporary order on their internal emotional chaos by enacting, then resolving, external chaos. The article does mention a few potential stages of mobilization, briefly referencing the perpetrator experimenting with identities and obtaining weapons for the attack. ${ }^{35}$ However, though the article presents a coherent theory explaining why individuals commit intimate massacres, there is no attempt at establishing a clear radicalization or mobilization timeline. In fact, it downplays the importance of a potential catalytic event, a key event in three of the four aforementioned processes, relying on long-term grievances as radicalizing factors but not addressing why intimate massacres occur at a given time.

In the absence of a dominant theory or a robust literature on theories, in a couple of cases authors have turned to general theories of violence - not theories specific to targeted violence - to make sense of these attacks. One article uses the $\mathrm{I}^{3}$ model, a theoretical framework that suggests that high degrees of instigation and impelling factors, when combined with limited inhibition, increase the likelihood of aggression. ${ }^{36}$ The article applies this model to a case study of James Holmes, arguing that a combination of severe mental illness and acute personal struggles guided him toward committing an act of targeted violence. ${ }^{37}$ Another article references the Path to Violence, the general theory of violence upon which the aforementioned Path to Intended Violence, Path to Terrorist Violence, and Path to Intended and Terroristic Violence are based. $^{38}$

\section{Case Studies and Comparative Analysis: Theories in Practice}

The lack of a robust literature on theories of radicalization or mobilization for those who commit acts of targeted violence is not necessarily indicative of a disciplinary short-coming or a theoretical lacuna. In fact, though recent scholarship suggests improvement, terrorism studies has been criticized repeatedly for producing too much theoretical literature (relying too heavily on the literature review methodology and lagging behind other fields in quantitative analysis) ${ }^{39}$ It may, as a result, be a poor point of comparison for assessing the literature on targeted violence. The absence of theories of radicalization or mobilization unique to perpetrators of targeted violence, however, raises the obvious question of how this process is being discussed. The

${ }^{35} \mathrm{Katz}$, “A theory of intimate massacres," 282.

${ }^{36}$ Clare S. Allely, "The contributory role of psychopathology and inhibitory control in the case of mass shooter James Holmes," Aggression and Violent Behavior 51 (2020): 8.

${ }^{37}$ Allely, "The contributory role of psychopathology and inhibitory control in the case of mass shooter James Holmes," 8.

${ }^{38}$ J. Reid Meloy and Jeffrey W. Pollard, "Lone-actor Terrorism and Impulsivity," Journal of Forensic Sciences 62, no. 6 (November 2017): 1644.

${ }^{39}$ John Horgan and Kurt Braddock, eds. Terrorism studies: A reader. Routledge, 2012; Bart Schuurman, "Research on terrorism, 2007-2016: A review of data, methods, and authorship," Terrorism and Political Violence 32, no. 5 (2020): 1011-1026; Andrew Silke and Jennifer Schmidt-Petersen, "The golden age? What the 100 most cited articles in terrorism studies tell us," Terrorism and Political Violence 29, no. 4 (2017): 692-712. 
dataset that we had assembled was well-suited to answer this question because it captured not only articles outlining theories of radicalization and mobilization, but also articles applying theories of radicalization and mobilization. Specifically, we identified 11 articles that explored - sometimes, but not always, as the primary thesis - the process by which an individual came to commit an act of targeted violence.

Because we knew that these case studies did not use the theories cited above, our expectation was that they would employ theories that come specifically from terrorism studies. This approach would be reasonable given recognition of the difficulty in clearly differentiating acts of targeted violence from acts of domestic terrorism. Additionally, such work does exist. As one example, Peterson and Densley, in their 2021 book The Violence Project, acknowledge that some mass shooters (e.g., Elliot Rodger) go through a radicalization process and cite terrorism studies scholar Fathali Moghaddam's staircase to terrorism. Surprisingly, though, this pattern was not evident in the case studies. In fact, despite being captured in our query (and thus including language suggestive of an interest in radicalization or mobilization), few of the case studies focused on these processes, focusing instead on risk factors and individual psychopathology. For example, the most highly cited article (according to Google Scholar), "The Autogenic (Self-Generated) Massacre," seeks to develop a profile of perpetrators of targeted violence by comparing five anonymized case studies. ${ }^{40}$ It finds, among other things, that all five actors were likely depressed, that most had obsessional tendencies, felt persecuted and self-righteous, and that all were socially isolated. ${ }^{41}$ The second most cited case study captured in our dataset applied psychoanalytic models to the Columbine High School shooters, presenting the shooting as a byproduct of "bully-victim-bystander dynamics" and emphasizing community responsibility for such attacks. ${ }^{42}$ Finally, the most recently published article closely examines the concept of pathological fixation, found to be a proximal warning sign for targeted violence, and uses seven case studies to exemplify three cognitive-affective drivers of fixation: delusion, extreme overvalued belief, and obsession. ${ }^{43}$ The authors focus in particular on extreme overvalued belief, using the case studies to 1) clarify the difference between it and delusion and 2) begin to draw out implications for threat assessment. ${ }^{44}$ These three articles, while not exhaustive in their coverage of the case study topics, are a representative sample of the targeted violence case

311.

${ }^{40}$ Paul E. Mullen, “The autogenic (self-generated) massacre," Behavioral Sciences and the Law 22 (2004):

${ }^{41}$ Mullen, "The autogenic (self-generated) massacre," 318-319.

${ }^{42}$ Stuart W. Twemlow, "The Roots of Violence: Converging Psychoanalytic Explanatory Models for Power Struggles and Violence in Schools," The Psychoanalytic Quarterly 69, no. 4 (2000): 775.

${ }^{43}$ J. Reid Meloy and Tahir Rahman, "Cognitive-affective drivers of fixation in threat assessment," Behavioral Sciences and the Law 39 (2021): 180; J. Reid Meloy, Jens Hoffmann, Angela Guldimann, and David James, "The Role of Warning Behaviors in Threat Assessment: An Exploration and Suggested Typology," Behavioral Sciences and the Law 30 (2012): 265.

${ }^{44}$ Two of the seven case studies are of individuals we have classified as terrorists-Timothy McVeigh and Nidal Malik Hasan; Meloy and Rahman, "Cognitive-affective drivers of fixation in threat assessment," 183. 
studies we identified; notably, none theorize an individual's full progression to committing an act of targeted violence.

Finally, we analyzed a set of articles that were explicitly comparative (i.e., that bridged the gap between targeted violence and domestic terrorism). Our queries returned 20 articles that fell into this category; these articles, in other words, both (a) addressed targeted violence and domestic terrorism and (b) contained at least some discussion of the process by which the individual came to commit an act of violence. Of these articles, however, only five included theories of radicalization and/or mobilization and all five of these were mentioned above.

Path to Intended and Terroristic Violence (Theory 3 above): One article in this category applied a targeted violence model of radicalization (Path to Intended and Terroristic Violence) to terrorist Anders Breivik. ${ }^{45}$ This article did not, however, aspire to make broad generalizations about the theory's utility as the theory was narrowly constructed to address a very small subset of violent perpetrators diagnosed with (or suspected to have) an ASD. ${ }^{46}$ Another article expanded somewhat on the Path to Violence model by exploring the role that impulsivity plays in accelerating individuals, perhaps even hastily, towards what might otherwise be described as carefully planned violence. ${ }^{47}$

Developmental Pathways to Demonstrative Targeted Violence Model (Theory 4 above): The two articles that mentioned this model are the same two that were described in the theory section above.

Importantly, all four of these articles used their respective models to explain both radicalization and mobilization, and all four described perpetrators of terrorist violence and targeted violence moving through the same process. ${ }^{48}$

Opinion Radicalization Theory: The final model that we found in the comparative literature was the Opinion Radicalization Theory, which focuses solely on the radicalization process. This theory comes from work by Leuprecht, Hataley, Moskalenko

${ }^{45}$ L. Faccini and C.S. Allely, "Mass violence in individuals with Autism Spectrum Disorder and Narcissistic Personality Disorder: A case analysis of Anders Breivik using the 'Path to Intended and Terroristic Violence' Model," Aggression and Violent Behavior 31 (November-December 2016).

${ }^{46}$ L. Faccini and C.S. Allely, "Mass violence in individuals with Autism Spectrum Disorder and Narcissistic Personality Disorder."

${ }^{47}$ Meloy and Pollard, "Lone-actor Terrorism and Impulsivity."

${ }^{48}$ Nils Böckler, Vincenz Leuschner, Viktoria Roth, Andreas Zick, and Herbert Scheithauer, "Blurred Boundaries of Lone-Actor Targeted Violence: Similarities in the Genesis and Performance of Terrorist Attacks and School Shootings," Violence and Gender 5, no. 2 (2018): 7-80; Nils Böckler, Vincenz Leuschner, Viktoria Roth, Andreas Zick, and Herbert Scheithauer, "Same but Different? Developmental Pathways to Demonstrative Targeted Attacks - Qualitative Case Analyses of Adolescent and Young Adult Perpetrators of Targeted School Attacks and Jihadi Terrorist Attacks in Germany," International Journal of Developmental Science 12 (2018): 5-24. 
and McCauley differentiating the radicalization to extremist ideologies from the radicalization to violent actions (some of which is mentioned in the introduction). ${ }^{49}$ Based on interviews with individuals who had expressed "deep interest" in school shootings, the article identified three tiers of actors within an opinion pyramid. The first tier includes individuals who are interested in school shootings but do not have positive associations with the events or the perpetrators. The second tier describes individuals who sympathize or identify with perpetrators or their actions, but do not condone shooters' violence or have interest in carrying out an attack of their own. The final tier consists of those who have interest in conducting their own massacres. The article made connections to the similarities of school shootings and terrorism, but did not attempt to apply the Opinion Radicalization Theory to other forms of targeted violence.

The remainder of the articles in this category did not articulate a model for the processes that they explored. Instead, four focused on mental health or personality traits of perpetrators that may suggest a predisposition to targeted or terrorist violence, ${ }^{50}$ four focused on categorizing the perpetrators motivations, ${ }^{51}$ and two foregrounded both risk factors and motivations. ${ }^{52}$ Finally, five articles examined the beliefs and behaviors of individuals planning or carrying out attacks, including how social networks may impact their radicalization or mobilization. ${ }^{53}$

\section{Conclusion}

In some ways, it is unsurprising that there is only a modest literature on radicalization processes for those who engage in acts of targeted violence. Radicalization has long been recognized as a belief- or thought-oriented process, and it is easy to understand why it has not

\footnotetext{
${ }^{49}$ Jenni Raitanen and Atte Oksanen, "Deep Interest in School Shootings and Online Radicalization," Journal of Threat Assessment and Management 6 (2016): 159-172.

${ }^{50}$ For example: Emily Corner, Paul Gill, and Oliver Mason, "Mental Health Disorders and the Terrorist: A Research Note Probing Selection Effects and Disorder Prevalence," Studies in Conflict and Terrorism 39 (2016); Emily Corner, Paul Gill, Ronald Schouten, and Frank Farnham, "Mental Disorders, Personality Traits, and Grievance-Fueled Targeted Violence: The Evidence Base and Implications for Research and Practice," Journal of Personality Assessment 100 (2018).

${ }^{51}$ Joel A. Capellan, "Lone Wolf Terrorist or Deranged Shooter? A Study of Ideological Active Shooter Events in the United States, 1970-2014," Studies in Conflict and Terrorism 38 (2015); Randy Borum, Robert Fein, and Bryan Vossekuil, "A dimensional approach to analyzing lone offender terrorism," Aggression and Violent Behavior 17 (2012): 389-396; Joel A. Capellan, Joseph Johnson, Jeremy R. Porter, and Christine Martin, "Disaggregating Mass Public Shootings: A Comparative Analysis of Disgruntled Employee, School, Ideologically motivated, and Rampage Shooters," Journal of Forensic Sciences 64 (2018): 814-823.

${ }^{52}$ For example: Ramón Spaaij, "The Enigma of Lone Wolf Terrorism: An Assessment," Studies in Conflict and Terrorism 33 (2010).

${ }^{53}$ For example: Tahir Rahman, "Extreme Overvalued Beliefs: How Violent Extremist Beliefs Become 'Normalized'," Behavioral Sciences 8 (2018); Thomas J. Holt, Joshua D. Freilich, Steven M. Chermak, Colleen Mills, and Jason Silva, "Loners, Colleagues, or Peers? Assessing the Social Organization of Radicalization," American Journal of Criminal Justice 44 (2019): 83-105; Paul Gill, James Silver, John Horgan, Emily Corner, and Noémie Bouhana, "Similar crimes, similar behaviors? Comparing lone-actor terrorists and public mass murderers," Journal of Forensic Sciences 66 (2021): 1797-1804.
} 
been adopted by scholars concerned with a type of violence characterized (at least in part) by its lack of "a clearly discernible political, ideological, or religious motivation." ${ }^{\text {" Th }}$ This feature of targeted violence obviously raises the question of whether or not it is useful for policy and practice to have a widely-accepted theory of radicalization for the actors who commit this type of violence. A focus on mobilization might, by contrast, make more sense and is to some degree already reflected in the literature. Four of the five theories outlined above (the Sequential Model, Unnamed Shame and Developmental Trajectories Model, Path to Violence, and Developmental Pathways to Demonstrative Target Attacks) are hybrid models that describe the related processes of radicalization and mobilization (i.e., that begin with changes in thoughts and beliefs, but that culminate in actions such as planning and/or attacking). Importantly, while there are no definitive models for radicalization or mobilization within terrorism studies, the four process-oriented models outlined above are consistent with many of the models that have been articulated within by experts in the field of terrorism (i.e., each begins with a source of stress or grievance, transitions through a period during which individual identity and the morality of violence are reexamined, and culminates with a commitment to or engagement in violent activity).

This literature review has, however, highlighted a number of critical issues that merit additional research. The issues outlined below are especially important as increased clarity would meaningfully contribute to our shared understanding of the similarities and differences between those who commit acts of targeted violence and those who commit acts of domestic terrorism with important implications for policy and practice.

1. Risk factors: The literature on targeted violence appears to to favor discussions related to risk factors over discussions related to radicalization and mobilization. As such, it should be possible to determine whether or not the individuals who commit acts of targeted violence share the same, or have different, risk factors from those who commit acts of domestic terrorism.

2. Risk and threat assessment: A number of tools have been developed, over the past two decades, to aid in the work of risk and threat assessment. A comparison of the tools discussed in these distinct literatures (i.e., targeted violence and domestic terrorism) could increase our knowledge in an area (risk and threat assessment) critically important to practitioners working in the two fields.

3. Incels: Our research team chose to classify incels as domestic terrorists for the purposes of this literature review, but we could have chosen to classify incels as targeted violence actors, or we could have chosen to classify each incel separately. Because the incel population's ideology is amorphous, and personal grievance is so central to many incels' motivations, it is possible that a review of the literature on incels (a population that

${ }^{54}$ U.S. Department of Homeland Security, Strategic Framework for Countering Terrorism and Targeted Violence (2019). 
perhaps bridges the gap between targeted violence and domestic terrorism) could be leveraged to explore the relationship between these two types of violence.

4. Social amplifiers: There is a relatively robust discussion within the targeted violence literature on a number of social factors (e.g., media violence, video games, contagion) that might increase the likelihood that acts of targeted violence will occur. A study designed to review this literature, and assess its applicability to domestic terrorists, could shed light on the similarities and differences between the two populations of actors.

A universal definition of terrorism remains elusive, and the work of defining targeted violence is not yet done (though DHS identified the need for a definition as a priority action item in its 2019 Strategic Framework) ${ }^{55}$ It is consequently difficult to assert the precise relationship between these threats, but it is equally difficult to deny or ignore the similarities between them. We may not yet--and if definitions continue to evade us, we may not ever--be able to explain precisely how these two are related. And yet the similarities are too compelling to ignore, and so additional research is necessary. This work, moreover, is especially critical because research on targeted violence and research on domestic terrorism is often being done by distinct sets of scholars, with distinct disciplinary backgrounds (research on targeted violence appears to be dominated by those working in the field of criminology and sociology, while research on domestic terrorism appears to be dominated by those with backgrounds in political science and psychology). These literatures are not, at present, in conversation with one another, and helping this to happen has the potential to meaningfully advance the understanding of both phenomena.

${ }^{55}$ U.S. Department of Homeland Security, Strategic Framework for Countering Terrorism and Targeted Violence. 